\title{
KONTRIBUSI KESEJAHTERAAN EKONOMI PERTAMBANGAN EMAS TERHADAP PENDAPATAN RUMAH TANGGA PEKERJA DAN PENDULANG DI NAGARI LUBUK GADANG KECAMATAN SANGIR KABUPATEN SOLOK SELATAN
}

\author{
Siska Yuliati \\ ${ }^{1}$ Program Studi Pendidikan Geografi - Jurusan Geografi \\ FakultasIlmuSosial, Universitas Negeri Padang \\ Email siskayuliati99@gmail.com
}

\begin{abstract}
Abstrak
Penelitian ini dilakukan di Nagari Lubuk Gadang Kecamatan Sangir Kabupaten Solok Selatan yang bertujuan untuk mendeskripsikan: (1) pendapatan pekerja dompeng dan pendulang emas,

(2) kontribusi pendapatan rumah tangga pekerja dompeng dan pendulang emas di Nagari Lubuk Gadang Kecamatan Sangir Kabupaten Solok Selatan. Jenis penelitian ini adalah deskriptif kuantitatif. Populasi penelitian ini adalah pekerja dompeng dan pendulang emas yang terdiri dari 1025 orang.Teknik pengambialan sampel adalah random sampling jumlah sampel ditetapkan menggunakan rumus slovin dengan sampelsebanyak 42 orang. Data yang di kumpulkan melalui penyebaran kuesioner atau angket. Hasil penelitian ini menunjukkankegiatan ekonomi yang dilakukan pekerja dompeng dan pendulang emas di Nagari Lubuk Gadang Kecamatan Sangir Kabupaten Solok Selatan memberikan (1)pendapatan pekerja dompeng dan pendulang emastelah memenuhi kebutuhan anggota rumah tangga pekerja dompeng dan pendulang emas. (2) Kontribusi ekonomi yang dilakukan oleh pekerja dompeng yaitu sebesar Rp 1.000.000 - Rp 20.000.000/bulan dan pendulang emas yaitu sebesar Rp 1.000.000 - Rp 16.000.000/bulan.
\end{abstract}

Kata Kunci : Kontribusi, Pertambangan dan Pendapatan

\begin{abstract}
This research was conducted in Nagari Lubuk Gadang Sangir Subdistrict of South Solok Regency which aims to describe: (1) Earnings of workers of dompeng and pendulang gold, (2) The contribution of household income of golden and gold pending workers in Nagari Lubuk Gadang Sangir Sub-district, South Solok District. This type of research is descriptive quantitative. The population of this research is workers of dompeng and pendulang gold consisting of 1025 people. Sample sampling technique is random sampling the number of samples determined using slovin formula with a sample of 42 people. Data collected through questionnaires or questionnaires. The results of this study indicate that economic activities performed by gold dumping and gold pending workers in Nagari Lubuk Gadang Sangir Subdistrict of Solok Selatan Regency provide (1) The income of dompeng workers and gold miners has met the needs of household members of dompeng workers and gold miners. (2) Economic contribution made by dompeng workers is Rp 1,000,000 $R p$ 20,000,000 /month and gold miners are $R p$ 1,000,000 - Rp 16,000,000 /month.
\end{abstract}

Keywords: Contribution, mining and income 


\section{PENDAHULUAN}

Nagari Lubuk Gadang merupakan salah satu Daerah atau wilayah di dunia yang mempunyai banyak kekayaan alam baik yang dapat diperbaharui maupun yang tidak dapat diperbaharui. Jenis kekayaan alam yang tidak dapat diperbaharui contohnya adalah sumber daya alam berupa tambang. Banyak sekali jenis bahan tambang yang ada di Indonesia, antara lain emas.

\section{Wilayah Nagari Lubuk} Gadang ini terdapat beberapa pertambangan emas yang dikelola oleh masyarakat untuk meningkatkan kesejahteraan hidup mereka dan meningkatkan pendapatan ekonomi mereka. Pertambangan emas ini dilakukan secara tradisional atau yang dikenal dengan nama "dulang emas" yang dilakukan oleh masyarakat yang bermukim disekitar kawasan hutan yang ada disekitar Nagari Lubuk Gadang Kecamatan Sangir Kabupaten Solok Selatan. Sebagian besar ekonomi masyarakat disini dari penghasilan tambang emas karena hasil pendapatan yang didapatkan lebih besar di bandingkan pekerjaan lainnya, seperti bertani, berkebun, karena membutuhkan waktu yang lebih lama. Untuk meningkatkan pendapatan ekonomi mereka, kehadiran pertambangan emas ini telah memberikan sumbangan ekonomi terhadap masyarakat, khususnya di Nagari Lubuk Gadang,
Kecamatan Sangir, Kabupaten Solok Selatan sumbangan tersebut adalah berupa keterlibatan masyarakat manjadi tenaga kerja pada usaha tambang emas, serta berbagai peluang usaha yang terbuka lebar sebagai akibat kehadiran tambang emas tersebut.Oleh karena itu perlu dilakukan kajian dalam hal kontribusi pertambangan emas terhadap pendapatan rumah tangga di Nagari Lubuk Gadang Kecamatan Sangir Kabupaten Solok Selatan.

Kontribusi berarti individu tersebut juga berusaha meningkatkanefisisensi dan efektivitas hidupnya (Fahrul dkk, 2018). Hal ini dilakukan dengan cara menajamkanposisi perannya, sesuatu yang kemudian mejadi bidang spesialis, agar lebih tepatsesuai dengan kompetensi. Kontribusi dapat diberikan dalam berbagai bidangyaitu pemikiran, kepemimpinan, profesionalisme, finansial, dan lainnya (AnneAhira, 2012).

Rumusan pengertian kontribusi yang dikemukakan di atas maka dapatdiartikan bahwa kontribusi adalah suatu keterlibatan yang dilakukan oleh individuatau sebuah lembaga yang kemudian memposisikan dirinya terhadap peran dalamsebuah kerja sama, dan memberikan dampak nilaidariaspek sosial danekonomi.

Menurut UU No 10 tahun 1992 yang dikatakan keluarga sejahtera adalah keluarga yang 
dibentuk berdasarkan atas perkawinan yang resmi mampu memenuhi kebutuhan hidup spiritual dan materil yang layak Bertakwa pada Tuhan yang Maha Esa, memiliki hubungan yang serasi.

Menurut Badan Pusat Statistik (2005); Suasti (2004), indikator yang digunakan untuk mengetahui tingkat kesejahteraan ada 14 indikator yaitu pendapatan, kepemilikan asset, luas lantai, jenis lantai, jenis dinding, fasilitas tempat buang air besar, sumber air minum, sumber penerangan yang digunakan, bahan bakar yang digunakan, pendidikan kepala rumah tangga, frekuensi makan dalam sehari, kebiasaan membeli daging, kemampuan membeli pakaian, dan kemampuan berobat ke puskesmas. Tingkat kesejahteraan merupakan konsep yang digunakan untuk menatakan kualitas hidup suatu masyarakat atau individu di suatu wilayah pada satu kurun waktu tertentu. Konsep kesejahteraan yang dimiliki bersifat relatif, tergantung bagaimana penilaian masing-masing individu terhadap kesejahteraan itu sendiri.

Partadiredja (2000); Al Maghribi (2018) mengemukakan bahwa pendapatan masyarakat adalah balas jasa sebagai pengambilan/penggunaan faktor produksi yang dimiliki. Selanjutnya dikatakan bahwa pendapatan masyarakat adalah nilai seluruh barang-barang dan jasa-jasa oleh suatu masyarakat dalam waktu satu tahun.Definisi di atas dapat disimpulkan bahwa pendapatan masyarakat adalah sejumlah nilai produksi barang dan jasa yang dihasilkan oleh masyarakat atau daerah dalam satu periode tertentu. Jadi pada prinsipnya, pendapatan seorang masyarakat dalam pendapat regional, karena masyarakat tersebut merupakan pemilik faktor produksi yang digunakan dalam suatu proses produksi di daerahya.

Badan Pusat Statistik(2011); Al Maghribi (2018); faktor-faktor yangmempengaruhi pendapatan adalah tinggi rendahnya pendapatan dipengaruhi oleh beberapa faktor antara lain:(a)Jenis pekerjaan atau jabatan,semakin tinggi jabatan seseorang dalam pekerjaan maka pendapatannya juga semakin besar, (b) Pendidikan,semakin tinggi pendidikan seseorang maka mengakibatkan jabatan dalam pekerjaan semakin tinggi dan pendapatan yang diperoleh juga semakin besar, (c) Masa kerja,masa kerja yang lama berpengaruh terhadap pendapatan, dimana masa kerja semakin lama pendapatan semakin besar, (d) Jumlah anggota keluarga,jumlah anggota keluarga yang banyak mempengaruhi jumlah pendapatan karena jika setiap anggota keluarga bekerja maka pendapatan yang diperoleh semakin besar.

Dalam arti sederhana pendapatan dapat pula diartikan 
sebagai total penerimaan setelah dikurangi dengan semua biaya (pengeluaran). Balas jasa yang diterima oleh pemilik faktor produksi yang dihitung dalam jangka waktu tertentu, bentuk dan jumlah pendapatan mempunyai fungsi yang sama yaitu untuk memenuhi kebutuhan sehari-hari dan memberi kepuasan, disamping itu pendapatan berfungsi pula untuk mencukupi kegiatan lain dan memenuhi kewajiban-kewajiban. Pendapatan tersebut dapat diperoleh dari berbagai sumber seperti hasil penjualan jasa, hasil penjualan barang dagangan, hasil penjualan produksi pertanian dan sumbersumber lainnya.

Pertambangan yang ada di Nagari Lubuk Gadang Kecamatan Sangir Kabupaten Solok Selatan ini merupakan tambang ilegal yang berdampak positif dan negatif, dampak positif meningkatkan pendapatan, sedangkan dampak negatifnya terhadap rusaknya lingkungan. Disuatu sisi kegiatan ekonomi yang dilakukan di Nagari Lubuk Gadang Kecamtan Sangir Kabupaten Solok Selatan adalah tambang ilegal yang bisa menyebakan rusaknya lingkungan, pencemaran air, pencemaran tanah. Namun disisi lain kegiatan ekonomi yang dilakukan di Nagari Lubuk Gadang Kecamatan Sangir Kabupaten Solok Selatan ini memberikan kontribusi yang cukup besar terhadap pekerja dompeng dan pendulang emas. Untuk lebih lanjutnya peneliti tertarik melakukan penelitian yang berjudul tentang

"Kontribusi Kesejahteraan Ekonomi Pertambangan Emas terhadap Pendapatan Pekerja dan Pendulang di Nagari Lubuk Gadang Kecamatan Sangir Kabupaten Solok Selatan”.

\section{METODOLOGI PENELITIAN}

Jenis penelitian ini adalah penelitian deskriptif kuantitatif. Dalam penggunaan metode deskriptif ini ada teknik perolehan utama yang digunakan dalam mengumpulkan imformasi atau data yang diperlukan antara lain: observasi, penyebaran kuesioner atau angket, dokumentasi, dan responden.

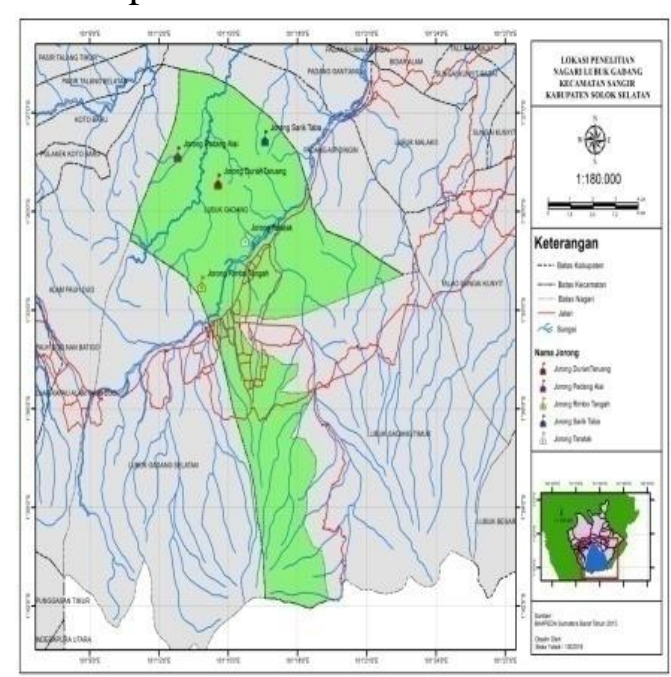

Gambar 1. Lokasi Penelitian

Teknik pengambilan sampel yang digunakan adalah teknik random sampling, berdasakan jumlah popoulasi sebnyak 1025 orang,sampel dalam penelitian ini sebanyak 42 orang dengan 
menggunakan rumus slovin. Rosady Ruslan (2003:24)

$$
\begin{gathered}
\mathrm{n}=\frac{N}{1+N(e)^{2}} \\
\mathrm{n}: \text { Jumlah Sampel } \\
\mathrm{N}: \text { Jumlah Populasi } \\
\text { e: Tingkat kesalahan }(15 \%)
\end{gathered}
$$

\section{HASIL DAN PEMBAHASAN}

Deskripsi Wilayah

Kenagarian Lubuk Gadang adalah Kenagarian yang terletak dipusat Pemerintah Kabupaten Solok Selatan. Ibu Kota Kabupaten Solok Selatan ditetapkan berkedudukan di Padang Aro, Kenagarian Lubuk Gadang Kecamatan Sangir.

Kenagarian Lubuk Gadang merupakan salah satu Nagari yang terdapat di Kecamatan Sangir. Luas Nagari Lubuk Gadang adalah 362,33 $\mathrm{km}^{2}$, dengan batas batas wilayah :Sebelah Utara dengan Nagari Lubuk Gadang Utara, sebelah Selatan dengan Nagari Lubuk Gadang Selatan, sebelah Timur dengan Nagari Lubuk Gadang Timur, sebelah Barat dengan Kenagarian Padang Air dingin Kecamtan Sangir Jujuan

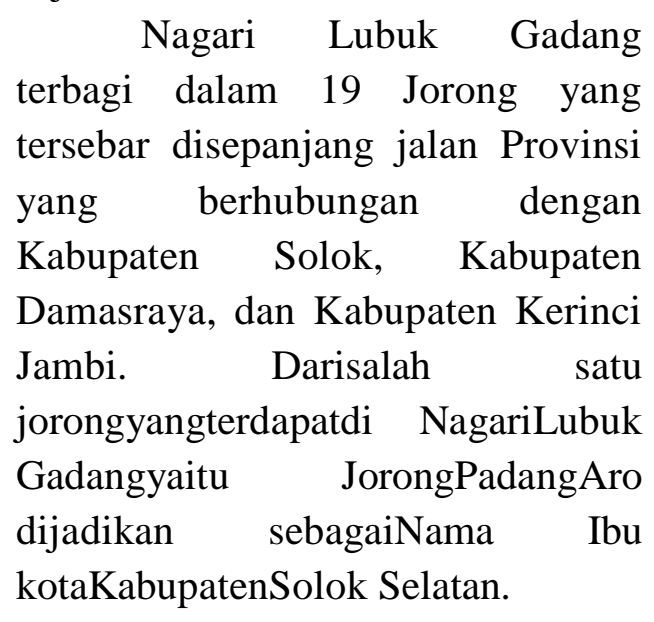

\section{Pendapatan Pekerja Dompeng dan Pendulang Emas/Bulan}

\begin{tabular}{|c|c|c|c|c|c|c|}
\hline No & Nama & $\begin{array}{l}\text { Pendapatan } \\
\text { (Rp) }\end{array}$ & $\begin{array}{l}\text { Pekeluaran } \\
\text { (Rp) }\end{array}$ & Plus (+) & Minus (-) & Persentase $(\%)$ \\
\hline 1 & Afrizal & 13.000 .000 & 3.950 .000 & 9.050 .000 & & \\
\hline 2 & Metri & 4.400 .000 & 2.030 .000 & 2.370 .000 & & \\
\hline 3 & Reflinda & 3000.000 & 3.640 .000 & & 640.000 & $-21,33$ \\
\hline 4 & Yesni & 4.330 .000 & 2.450 .000 & 1.180 .000 & & 43,41 \\
\hline 5 & Afwandi & 5.000 .000 & 4.950 .000 & 50.000 & & 1 \\
\hline 6 & Syafri Joniang & 10.000 .000 & 4.200 .000 & 5.800 .000 & & 58 \\
\hline 7 & Julaini & 13.8000 & 4.875 .000 & 8.925 .000 & & 64,67 \\
\hline 8 & Yomi & 4.000 .000 & 4.200 .000 & & 200.000 & -5 \\
\hline 9 & Nella & 14.000 .000 & 4.150 .000 & 9.850 .000 & & 70,35 \\
\hline 10 & Anto & 4.000 .000 & 3.450 .000 & 550.000 & & 13,75 \\
\hline 11 & Ijal & 3.000 .000 & 3.740 .000 & & 740.000 & $-24,66$ \\
\hline 12 & Afrisan & 6.500 .000 & 4.020 .000 & 2.480 .000 & & 38,15 \\
\hline 13 & Ilyas & 5.000 .000 & 3.740 .000 & 1.260 .000 & & 25,2 \\
\hline 14 & Meri & 5.000 .000 & 3.480 .000 & 1.160 .000 & & 23,2 \\
\hline 15 & Yeli & 8.400 .000 & 3.205 .000 & 5.195 .000 & & 61,84 \\
\hline 16 & Nada & 11.650 .000 & 2.855 .000 & 8.795 .000 & & 75,49 \\
\hline 17 & Ija & 11.100 .000 & 4.380 .000 & 6.720 .000 & & 60,54 \\
\hline 18 & Hamdani & 9.200 .000 & 6.480 .000 & 2.720 .000 & & 29,56 \\
\hline 19 & Ahmad Rusdi & 2.650 .000 & 3.020 .000 & & 370.000 & $-13,69$ \\
\hline 20 & Ahmad Rusdi & 15.000 .000 & 7.500 .000 & 7.500 .000 & & 50 \\
\hline 21 & Jamal & 10.330 .000 & 3.580 .000 & 6.750 .000 & & 65,34 \\
\hline 22 & Peri & 5.000 .000 & 2.050 .000 & 2.950 .000 & & 59 \\
\hline 23 & Ijul & 8.000 .000 & 6.790 .000 & 1.210 .000 & & 15,12 \\
\hline 24 & Rido & 14.000 .000 & 2.800 .000 & 11.200 .000 & & 80 \\
\hline 25 & Iyel & 6.000 .000 & 4.850 .000 & 1.150 .000 & & 19,16 \\
\hline 26 & Faisal & 6.000 .000 & 4.950 .000 & 1.050 .000 & & 17,5 \\
\hline 27 & Filda & 6.000 .000 & 4.350 .000 & 1.650 .000 & & 27,5 \\
\hline 28 & Ijar & 6.000 .000 & 3.900 .000 & 2.100 .000 & & 35 \\
\hline 29 & Nuryenti & 5.000 .000 & 3.030 .000 & 970.000 & & 19.4 \\
\hline 30 & Nulena & 14.000 .000 & 6.700 .000 & 7.300 .000 & & 52,14 \\
\hline
\end{tabular}

\section{a. Pendapatan Pendulang Emas}

Tabel 1. Total Pendapatan dan Pengeluaran

Anggota Rumah Tangga Pendulang Emas 


\begin{tabular}{|l|l|l|l|l|r|r|}
\hline 31 & Ramalis & 14.000 .000 & 2.300 .000 & 11.700 .000 & & 0.85 \\
\hline 32 & Fauzan & 16.000 .000 & 1.610 .000 & 14.390 .000 & 89.93 \\
\hline \multicolumn{3}{|c|}{ Jumlah } & \multicolumn{3}{|c|}{32} & \\
\hline
\end{tabular}

Sumber: Data Primer 2017 dari Responden yang di olah

Berdasarkan tabel 1 dapat memenuhi kebutuhan pendapatan pendulang emas adalah sebesar Rp.1.000.000Rp.16.000.000/bulannya. Dengan anggota rumah tangga pendulang enmas tersebut, dan pendapatan pendapatan pendulang sebesar itu seimbang dengan pengeluaran kebutuhan anggota rumah tangga.

\section{b. Pendapatan Pekerja Dompeng}

Tabel 2. Total Pendapatan dan Pengeluaran

Anggota Rumah Tangga Pekerja Dompeng

\begin{tabular}{|l|l|r|r|r|r|c|}
\hline No & Nama & Pendapatan (Rp) & $\begin{array}{c}\text { Pengeluaran } \\
(\mathrm{Rp})\end{array}$ & Plus(+) & Minus(-) & Persentase (\%) \\
\hline 1 & Jhoni Azwar & 26.850 .000 & 5.155 .000 & 21.695 .000 & - & 80,80 \\
\hline 2 & Roby & 38.000 .000 & 4.780 .000 & 33.220 .000 & - & 87,42 \\
\hline 3 & Ramadhanius & 3.520 .000 & 3.350 .000 & 170.000 & - & 4,82 \\
\hline 4 & Syahril Efendi & 12.800 .000 & 5.620 .000 & 7.180 .000 & - & 56,09 \\
\hline 5 & Riski & 2.000 .000 & 1.800 .000 & 200.000 & - & 10 \\
\hline 6 & Siska & 7.000 .000 & 2.840 .000 & 4.160 .000 & - & 59,42 \\
\hline 7 & Andreal & 5.500 .000 & 2.950 .000 & 2.550 .000 & - & 46,36 \\
\hline 8 & Afrida Yeni & 8.000 .000 & 2.300 .000 & 6.700 .000 & - & 83,75 \\
\hline 9 & Zilfa & 3.600 .000 & 2.450 .000 & 1.150 .000 & - & 31,94 \\
\hline 10 & Rehan & 20.000 .000 & 4.300 .000 & 15.700 .000 & - & 78,5 \\
\hline
\end{tabular}

Berdasarkan tabel 2 rata-rata pendapatan pekerja dompeng $\mathrm{Rp}$. 1.000.000-Rp.16.000.000/bulannya. Dengan pendapatan pekerja sebesar ini telah mencukupi kebutuhananggota rumah tangga mereka dan pendapatan seimbang dengan pengeluaran anggota rumah tangga pekerja dompeng.

Berdasarkanhasil analisis pendapatan pekerja dompeng dan pendulang emas terdapat perbandingan pendapatan pekerja dompeng dan pendulangn emas, dimana pendapatan yang di peroleh oleh pekerja dompeng yaitu sebesar Rp.1000.000-20.000/bulannya, sedangkan pendapatan yang diperoleh oleh pendulang emas yaitu sebesar Rp.1000.00016.000.000/bulannya. Perbandingan pendapatan ini disebabkan oleh perbedaan alat yang mereka gunakan dan waktu kerja mereka untuk melakukan kegiatan tambang, pekerja dompeng ini memiliki alat yang lebih canggih untuk menggali lobang sedalam-dalam mungkin, sehingga mereka menemukan dimana posisi emas terbanyak, dengan menggunakan alat mesin, seperti Ekskavator (penggali lobang),Mesin Dompeng (mendeteksi keberadaan emas), Mesin Rubin (mendeteksi emas) dan Asbuk (menyaring antara emas dan pasir), sehingga pekerja bisa menghasilkan emas lebih banyak. Sedangkan pendulang emas hanya menggunakan alat tradisional untuk mendapatka emas, seperti Jae( pendulang emas), Patok kelapa 
(mengambil pasir atau tanah), Karung ( meletakkan pasir atau tanah yang diambil dari lobangyang telah digali pekerja dompeng dan Linggis( untuk menggali lobang atau mencongkel pasir pada dindingdinding lobang yang telah digali pekerja dompeng). Sehinnga mereka memperoleh penghasilan yang lebih kecil dibandingkan pekerja dompeng, pendulang hanya bias mengambil pasir atau tanah dari sisasisa pekerja dompeng dilobang galian pekerja dompeng.

\section{Kontribusi Pendapatan Rumah} tangga Pekerja Dompeng dan Pendulang Emas

Kontribusi ekonomi yang di lakukan oleh pekerja dompeng yaitu sebesarRp.1000.000-Rp.

20.000.000/bulannya dan pendulang emas yaitu sebesar Rp. 1.000.00016.000.000/bulannya di Nagari Lubuk Gadang Kecamatan Sangir Kabupaten Solok Selatan ini cukup besar terhadap pendapatan pekerja dompeng dan pendulang emas.

\section{KESIMPULAN DAN SARAN}

\section{Kesimpulan}

Berdasakan hasil dan
pembanhasan penelitian, maka
kesimpulannya adalah pendapatan
pekerja dompeng dan pendulang
emas yang diperoleh dari kegiatan
penambang, ternyata dapat memenuhi kebutuhan anggota rumah tangga pekerja dompeng dan pendulang emas. Hal ini lah yang menyebabkan pekerja dompeng dan pendulang emas terus-menerus melakukan kegiatan ekonomi penambang emas, karena untung yang mereka peroleh dari penambang emas ini cukup besar sehingga dapat memenuhi kebutuhan anggota rumah tangga mereka. Kontribusi ekonomi yang di lakukan oleh pekerja dompeng yaitu sebesarRp.1000.000-

20.000.000/bulannya dan pendulang emas yaitu sebesar Rp.1.000.000$16.000 .000 /$ bulannya di Nagari Lubuk Gadang Kecamatan Sangir Kabupaten Solok Selatan ini cukup besar terhadap pendapatan pekerja dompeng dan pendulang emas.

\section{Saran}

Berdasarkan hasil penelitian dan kesimpulan yang dikemukakan di atas maka peneliti memberikan saran sebagai berikut :

1. Bagi pemerintah seharus lebih mengembangkan kegiatan pertambangan yang berbasis lingkungan agar masyarakat itu lebih sejahtera lagi karena hasil dari pendapatan pertambangan itu lebih besar dibandingkan pekerjaan yang lainnya.

2. Bagi masyarakat lebih berhatihati lagi untuk bekerja di pertambangan itu karena bekerja disana sangat membahayakan diri, bahkan biasa merengkut nyawa sendiri, walaupun hasilnya lebih besar.

3. Hasil dari peneltian ini diharapkan mampu memberikan mamfaat bagi ilmu pengetahuan 
sosial, dan dapat dijadikan salah satu reverensi terkait penelitian kontribusi kesejahteraan ekonomi pertambangan emas tehadap pendapatan yang merupakan pengembangan ilmu geografi dalam bidang ilmu geografi ekonomi.

\section{DAFTAR PUSTAKA}

Al Maghribi, R., Suasti, Y dan Wilis, R. 2018. MULTIPLIER EFFECT PERTANIAN NANAS (Ananas Comosus) TERHADAP PENYERAPAN TENAGA KERJA DAN PENDAPATANMASYARAK AT DI DESA KUALU NANAS, KECAMATAN TAMBANG, KABUPATEN KAMPAR, PROVINSI RIAU. JURNAL BUANA, 1(1), 88-88.

Anne Ahira, 2012. "Kontribusi",http://id.wikipe dia.org/Kontribusi.

Badan Pusat Statistik Antar Sensus 2005. Jakarta Pusat.

BPS Sumatera Barat (2011).Penduduk Sumatera Barat. Jakarta. Indonesia.

UU No.10 tahun 1992 indikatorindicator kesejateraan penduduk.

Fahrul, V., Suasti, Y dan Febriandi. 2018. ANALISIS POTENSI SUMBER DAYA MANUSIA NAGARI PARIANGAN KABUPATEN TANAH
DATAR. JURNAL BUANA, 1(1), 102-102.

Partadiredja, 2000."PendapatanRumah

Tangga.

repository.uinsuska.ac.id/6526/ 4/BA B III.pdf.

Rosady Ruslan, 2003. "Metode Penelitian Public Relations dan Komunikasi”, (Jakarta: Rajawali Pers,), hal. 24.

Suasti, Y. (2004). Laporan penelitian fertilitas dan persoalan kesehatan reproduksi di perdesaan Padang Pariaman. Fakultas Ilmu-Ilmu Sosial, Universitas Negeri Padang. 